\title{
Ensaios antifúngicos com Schinus terebinthifolius Raddi (Aroeira vermelha) em cepas de Candida spp.: levantamento bibliográfico
}

O presente estudo teve por objetivo promover um levantamento bibliográfico nas bases de dados em torno da seguinte questão norteadora: quais os estudos referentes à utilização da espécie Schinus terebinthifolius Raddi em ensaios antifúngicos do gênero Candida em um período de 10 anos de produtividade científica? Trata-se de uma revisão integrativa da literatura de caráter descritivo, transversal com abordagem quantitativa. Obteve-se um quantitativo total de 26 artigos, contudo, apenas 10 passaram por leitura na íntegra para discussão, LILACS dois artigos, Medline seis e SciELO dois, sendo os demais descartados por não atenderem aos critérios estabelecidos. O estudo indicou pouca produtividade cientifica envolvendo a espécie Schinus terebinthifolius Raddi em relação ao gênero Candida, por mais que os existentes nas bases de dados tenham demostrado um potencial promissor na inibição de crescimento desse patógeno.

Palavras-chave: Aroeira-vermelha; Candida; Produtos naturais.

\section{Antifungal tests with Schinus terebinthifolius Raddi (Aroeira Vermelha) on strains of Candida spp.: bibliographical survey}

The present study aimed to promote a bibliographic survey in the databases around the following guiding question: what studies refer to the use of the species Schinus terebinthifolius Raddi in antifungal tests of the genus Candida in a period of 10 years of scientific productivity? It is an integrative review of the literature of a descriptive character, transversal with a quantitative approach. A total amount of 26 articles was obtained, however, only 10 were read in full for LILACS discussion with 2, Medline 6 and SciELO 2, the others were discarded because they did not meet the established criteria. The study indicated little scientific productivity involving the species Schinus terebinthifolius Raddi in relation to the genus Candida, even though the existing ones in the databases have shown a promising potential in inhibiting the growth of this pathogen.

Keywords: Red Aroma; Candida; Natural products.

Topic: Uso Sustentável da Biodiversidade

Reviewed anonymously in the process of blind peer.
Received: 01/12/2020

Approved: $23 / 12 / 2020$
Francisco Glauber Peixoto Ferreira (iD)

Universidade da Integração Internacional da Lusofonia Afro-Brasileira, Brasil http://lattes.cnpq.br/6898728780485440

http://orcid.org/0000-0002-3980-7253

fgpf.glauber@hotmail.com

\section{Meiriane da Silva Pinheiro (id}

Universidade da Integração Internacional da Lusofonia Afro-Brasileira, Brasil http://lattes.cnpq.br/3977098368007773

http://orcid.org/0000-0002-2643-8911

meirianehistoriadora@gmail.com

Bárbara Eleodora Santiago Gomes (iD)

Universidade da Integração Internacional da Lusofonia Afro-Brasileira, Brasil http://lattes.cnpq.br/7504427306460282

http://orcid.org/0000-0003-2872-9322

barbara@unilab.edu.br
Hudson Pimentel Costa (D)

Universidade da Integração Internacional da Lusofonia Afro-Brasileira, Brasil http://lattes.cnpq.br/1075491623486578

http://orcid.org/0000-0002-9973-6100

hpimentelcostaunilab@gmail.com

Juliana Jales de Hollanda Celestino ic

Universidade da Integração Internacional da Lusofonia Afro-Brasileira, Brasil http://lattes.cnpq.br/1526422544963342

http://orcid.org/0000-0002-9930-7541

juliana.celestino@unilab.edu.br

Maria Ivanilda de Aguiar (iD

Universidade da Integração Internacional da Lusofonia Afro-Brasileira, Brasil http://lattes.cnpq.br/5455983813192128

http://orcid.org/0000-0002-6147-2621

ivanilda@unilab.edu.br
Referencing this:

FERREIRA, F. G. P.; PINHEIRO, M. S.; GOMES, B. E. S.; COSTA, H. P.; CELESTINO, J. J. H.; AGUIAR, M. I.. Ensaios antifúngicos com Schinus terebinthifolius Raddi (Aroeira vermelha) em cepas de Candida spp.: levantamento bibliográfico. Revista Ibero Americana de Ciências Ambientais, v.11, n.7, p.235-242, 2020. DOI:

http://doi.org/10.6008/CBPC2179-6858.2020.007.0021 


\section{INTRODUÇÃO}

O uso de plantas medicinais é um hábito que ultrapassa gerações, e essas podem ser definidas como espécies que produzem um determinado princípio ativo, de modo a alterar as funções de órgãos e sistemas, visando a cura ou restauração de equilíbrio no combate a determinadas patologias (DUARTE et al., 2020). Tais efeitos terapêuticos são enraizados por meio de um conhecimento milenar pertencente às comunidades mais tradicionais, por meio de ensinamentos e práticas que muitas vezes não são respaldadas em materiais científicos.

Ainda dentro dessa ótica, tal prática envolve fatores como socioculturais e econômicos, uma vez que na maior parte do país, o acesso aos serviços de saúde torna-se restrito por motivos de distanciamento ou até mesmo baixo poder aquisitivo na obtenção de medicamentos industrializados e sintéticos. Contudo, boa parte desses produtos podem trazer riscos aos seus consumidores por não possuir um efeito tão elucidado, como é o caso da intoxicação por meio desses fitoterápicos alternativos de propriedades desconhecidas (ALBUQUERQUE et al., 2020).

Paralelamente ao assunto, o Decreto no 5.813, de 22 de junho de 2006, referente a Política Nacional de Plantas Medicinais e Fitoterápicos (PNPMF), preconiza em suas diretrizes, garantir e promover a segurança, a eficácia e a qualidade no acesso às plantas medicinais e fitoterápicos, além de reconhecer as práticas populares e medicamentos caseiros, à medida que estabelece a adoção de boas condutas de cultivo e manipulação de espécies naturais a partir de uma legislação específica (SOUZA-MOREIRA et al., 2010).

Nessa perspectiva, podemos citar a Schinus Terebinthifolius Raddi, popularmente conhecida como "Aroeira-vermelha", que em território brasileiro é utilizada como árvore de ornamentação, por possui grande beleza e presença robusta no que tange a sua morfologia. Além disso, seu uso é bem amplo, principalmente na farmacoterapia popular (SANTOS et al., 2020). Quanto a sua taxonomia, essa planta pertence ao reino vegetal, de origem ou divisão Tracheophyta, da classe Magnoliopsida, da ordem Sapindales, da família Anacardiaceae, gênero Schinus, espécie terebinthifolius, da subespécie Raddi (RUAS, 2016).

Nesse intuito, a S. terebinthifolius torna-se uma grande alternativa quando ao uso em biotecnologia, de modo a apresentar bons resultados em atividade antimicrobiana, especificamente no que se refere a seu fruto, em que demostrou em um experimento com Staphilococcus aureus coagulase positiva, resultados bem promissores (SILVA et al., 2010). Em complemento, seu extrato alcoólico combateu espécies como S. aureus, Bacilo cereus, Pseudomonas aeruginosa e Escherichia coli, além de inibição fúngica (SÁ JUNIOR et al., 2016). Há também evidências cientificas de que o extrato vegetal também apresentou efeito contra a espécie Enteroccocus faecalis em teste de sensibilidade de cultura (COSTA et al., 2010).

Ao tratarmos de estudos fúngicas em específico, um dos gêneros mais prevalentes na patogenicidade humana é a Candida. Com isso, a candidíase pode ser definida como uma doença oportunista, causada por leveduras, principalmente as espécies Candida albicans, Candida não-albicans, como C. glabrata, C. tropicalis, C. parapsilosis, C. krusei; e recentemente analisada, a C. dubliniensis (QUINDÓS, 2002; SIDRIM et al., 1999; WHITE et al., 2004). 
Esse gênero pertence à microbiota natural do indivíduo saudável, contudo, quando há um desequilíbrio imunológico, esse fungo torna-se patogênico ao hospedeiro, de maneira a causar determinados malefícios. Dessa forma, as manifestações clínicas causadas pela candidíase são bem variadas, de maneira a causar desde uma infecção localizada na mucosa, até uma condição clínica disseminada, que pode levar o indivíduo à morte, como é o caso de uma septicemia (NEGRI et al., 2012).

Recentemente, a espécie $C$. albicans tem mostrado um mecanismo de resistência farmacológica aos fármacos sintéticos, sendo isso justificado pela presença de biofilme. Diante dos fatos, o pouco arsenal medicamentoso juntamente com a mutação do microrganismo, pode ocasionar danos ao indivíduo sem uma intervenção eficaz. Nesse pressuposto, incentiva a busca por novas alternativas, como é o caso do produto natural mencionado.

Com base no exposto, formulou-se a seguintes questão norteadora: quais os estudos referentes a utilização da espécie Schinus terebinthifolius Raddi em ensaios antifúngicos do gênero Candida em um período de 10 anos de produtividade científica? Dessa forma, o presente estudo teve por objetivo promover um levantamento bibliográfico nas bases de dados dentro do referente temático.

\section{METODOLOGIA}

Trata-se de uma revisão integrativa da literatura de caráter descritivo, transversal com abordagem quantitativa. Nesse quesito, esse método possibilita a obtenção de dados no intuito de construir conhecimentos por meio do balanceamento produtivo e científico. Com isso, aponta caminhos dentro de uma determinada temática e seu percurso no decorrer do tempo, com aplicabilidade no surgimento de novos trabalhos, conforme necessidade e apontamentos encontrados por meio da busca (BROOME, 2006).

Ao longo desse estudo, a revisão da literatura seguiu um processo linear e sistemático, de modo a construir etapas em prol dos resultados. Optou-se pelo método proposto por Souza et al. (2010), no qual se remete em identificar o problema, e por meio deste formular a pergunta norteadora para ser pesquisada nas bases de dados com os descritores estabelecidos; definir critérios de inclusão e exclusão para realização do levantamento de dados; identificação dos estudos selecionados; categorização; interpretação dos resultados e análises; além da síntese do conhecimento construído.

Sob tal enfoque e conforme já mencionado anteriormente, em cima da problemática se questionou sobre 'Quais os estudos referentes a utilização de extratos medicinais com a espécie Schinus terebinthifolius Raddi em ensaios antifúngicos do gênero Candida em um período de 10 anos de produtividade científica?'. Como bases de dados utilizou-se a Literatura Latino-Americana em Ciências de Saúde (LILACS), Medical Literature Analysis and Retrieval Sistem on-line (Medline) e Scientific Electronic Library Online (SciELO).

Durante a pesquisa nas duas primeiras bases de dados, LILACS e Medline, foram utilizados os operadores booleanos 'and' em todos os descritores de pesquisa, que resultou em: 'Aroeira-vermelha' AND 'Candida' AND 'Biofármacos', respectivamente. Na terceira e última base de dados, SciELO, não foi possível utilizar os descritores boleanos dessa forma, em que foi utilizado 'or, and e and', que resultou em: 'Aroeiravermelha' $O R$ 'Candida' $O R$ 'Biofármacos'. Em complemento, na língua inglesa se traduziu em 'Red mastic' 
AND 'Candida' AND 'Biopharmaceuticals'. Já no idioma espanhol, remeteu-se a 'Aroma rojo' AND 'Candida' AND 'Productos biofarmacéuticos'. O espaço temporal foi estabelecido do ano de 2010 a 2020, no intuito de traçar uma linha cronológica até os dias atuais, de maneira sincronizada.

Após a busca, os artigos foram selecionados conforme os critérios de exclusão, ao qual corresponderam: aqueles que apresentavam duplicidade, artigos de revisão, teses, dissertações e trabalhos de conclusão de curso, com data de publicação fora do período estabelecido, e os que fugiram a questão norteadora. Em seguida, o material passou pelo procedimento de fichamento para organização dos dados e análise por meio de leitura na integra.

\section{RESULTADOS E DISCUSSÃO}

Após a busca, obteve-se um quantitativo total de 26 artigos, dos quais na base de dados LILACS, dois foram excluídos por não atenderem a questão norteadora. Já na Medline, dos 18 trabalhos, apenas seis se enquadravam na proposta, enquanto que os demais se encontravam fora do período estabelecido e sem disponibilidade na íntegra. Em contrapartida, na SciELO dois artigos foram descartados, por não envolver a espécie foco da pesquisa, conforme encontra-se exposto no Quadro 1.

Ainda nesse aspecto, uma particularidade encontrada foi com relação ao descritor principal em que se remeteu ao nome popular da planta em questão, ou seja, 'Aroeira-vermelha' ao invés de 'Schinus terebinthifolius Raddi', de forma que houve uma inversão de termos quanto a busca em bases de dados de caráter científico. A propósito dessas informações, é visivelmente aceito que as referências da planta têm origem Quilombola, mas que já foi explorada em estudos prévios (OLANDA et al., 2020). No entanto, observase a permanência ainda do nome popular no processo de busca em pleno ano de 2020, com desatualização quanto a sua taxonomia nos portais de busca.

Em contrapartida, por se tratar de uma planta já com exsicata, o emprego mais leigo ainda é bastante presente em trabalhos de modalidades socioculturais. Cabe aqui, traçarmos um paralelo no que se refere a necessidade da realização de experimentos na utilização dessas espécies e empregar rotineiramente suas taxonomias a fim de facilitar a compreensão de dados secundários e aproximar a teoria composta na literatura, com a prática usual desses produtos, inclusive com base em sua regulamentação e uso (PRIVATO et al., 2020).

Quadro 1: Fase de seleção dos estudos encontrados para compor a revisão dentro do período de 2010 a 2020 em estudos antifúngicos com cândida por meio de extratos de Schinus Terebinthifolius.

\begin{tabular}{|l|l|l|l|l|}
\hline Base de dados & Total encontrado & (inclusão/exclusão) & Fichamento: Leitura de resumo & Leitura na íntegra \\
\hline LILACS & 4 & 2 & 2 & 2 \\
\hline Medline & 18 & 12 & 6 & 6 \\
\hline SciELO & 4 & 2 & 2 & 2 \\
\hline TOTAL & $\mathbf{2 6}$ & $\mathbf{1 6}$ & $\mathbf{1 0}$ & $\mathbf{1 0}$ \\
\hline
\end{tabular}

Ainda em relação aos resultados, no decorrer da leitura final e conforme estabelecido em método por meio de fichamento, notou-se que a maior parte dos artigos foram publicados no idioma inglês, com sua maioria nos primeiros cinco anos no período de 2010 a 2020 (Quadro 2). Curiosamente, essa modalidade investigativa vem ganhando bastante espaço, principalmente pelo motivo da escassez de medicamentos e o 
aumento da resistência microbiológica, em especial as do Gênero Candida com relação a produção de biofilme (BERMÚDEZ et al., 2020). Porém, quanto a referente planta, ainda há um espaço lacunar nos cinco anos subsequentes na busca aqui estabelecida.

É possível notar também que o maior número de artigos foi encontrado na Medline (Quadro 1), com predominância entre os anos de 2012 e 2013. Nessa perspectiva, subtende-se um momento estacionário de sete anos quanto à aplicabilidade da Schinus terebinthifolius Raddi em ensaios antifúngicos. A planta possui outros focos na literatura, como é o caso de propriedades anti-inflamatórias (ROSAS et al., 2019), sendo que já com ênfase em estudos microbiológicos, pode-se perceber um declínio nos últimos tempos.

Quadro 2: Identificação e objetivo dos artigos selecionados para compor a revisão.

\begin{tabular}{|c|c|c|c|c|c|}
\hline $\begin{array}{c}\text { Base de } \\
\text { dados }\end{array}$ & Título & Idioma & Autores & Revista & $\begin{array}{c}\text { Ano de } \\
\text { publicação }\end{array}$ \\
\hline LILACS & $\begin{array}{l}\text { Activity of the aqueous extract } \\
\text { of Schinus terebinthifolius } \\
\text { Raddi on strains of the Candida } \\
\text { genus / Atividade do extrato } \\
\text { aquoso de Schinus } \\
\text { terebinthifolius Raddi sobre } \\
\text { cepas do gênero Candida }\end{array}$ & Inglês & $\begin{array}{l}\text { Torres, Kátia } \\
\text { Andrea de } \\
\text { Menezes; Lima, } \\
\text { Sônia Maria } \\
\text { Rolim Rosa; et al. }\end{array}$ & $\begin{array}{l}\text { Rev. bras. ginecol. obstet; } \\
\text { 38(12): 593-599. } 2012 \text {. }\end{array}$ & 2012 \\
\hline LILACS & $\begin{array}{l}\text { In vitro activity of Schinus } \\
\text { Terebinthifolius (Brazilian } \\
\text { pepper tree) on Candida } \\
\text { tropicalis growth and cell wall } \\
\text { formation }\end{array}$ & Inglês & $\begin{array}{l}\text { Alves, Livia A; } \\
\text { Freires, Irlan de } \\
\text { A; Souza, Tricia } \\
\text { M. P. A. de; et al. }\end{array}$ & $\begin{array}{l}\text { Acta odontol. latinoam ; 25(3): } \\
287-292,2012 .\end{array}$ & 2012 \\
\hline MEDILINE & $\begin{array}{l}\text { Influence of Culturing } \\
\text { Conditions on Bioprospecting } \\
\text { and the Antimicrobial Potential } \\
\text { of Endophytic Fungi from } \\
\text { Schinus terebinthifolius. }\end{array}$ & Inglês & $\begin{array}{l}\text { Tonial F; Maia } \\
\text { BH; Gomes- } \\
\text { Figueiredo JA; } \\
\text { Sobottka AM; } \\
\text { Bertol CD; Nepel } \\
\text { A; et al. } \\
\end{array}$ & $\begin{array}{l}\text { Curr. Microbiol;72(2):173-83, } \\
2016\end{array}$ & 2016 \\
\hline MEDLINE & $\begin{array}{l}\text { Antiadherent activity of } \\
\text { Schinus terebinthifolius and } \\
\text { Croton urucurana extracts on } \\
\text { in vitro biofilm formation of } \\
\text { Candida albicans and } \\
\text { Streptococcus mutans. }\end{array}$ & Inglês & $\begin{array}{l}\text { Ulukanli Z; } \\
\text { Karabörklü S; } \\
\text { Bozok F; Çenet } \\
\text { M; Oztürk B; } \\
\text { Balcilar M }\end{array}$ & $\begin{array}{l}\text { Nat Prod Res;28(23):2150-7, } \\
2014 .\end{array}$ & 2014 \\
\hline MEDLINE & $\begin{array}{l}\text { Antiadherent activity of } \\
\text { Schinus terebinthifolius and } \\
\text { Croton urucurana extracts on } \\
\text { in vitro biofilm formation of } \\
\text { Candida albicans and } \\
\text { Streptococcus mutans. }\end{array}$ & Inglês & $\begin{array}{l}\text { Barbieri DS; } \\
\text { Tonial F; Lopez } \\
\text { PV; Sales Maia } \\
\text { BH; Santos GD; } \\
\text { Ribas MO; et al. }\end{array}$ & $\begin{array}{l}\text { Arch Oral Biol;59(9):887-96, } \\
2014\end{array}$ & 2014 \\
\hline MEDLINE & $\begin{array}{l}\text { Antimicrobial activity of } \\
\text { Schinus lentiscifolius } \\
\text { (Anacardiaceae). }\end{array}$ & Inglês & $\begin{array}{l}\text { Gehrke IT; Neto } \\
\text { AT; Pedroso M; } \\
\text { Mostardeiro CP; } \\
\text { et al. }\end{array}$ & $\begin{array}{l}\text { J Ethnopharmacol;148(2):486- } \\
\text { 91, } 2013\end{array}$ & 2013 \\
\hline MEDLINE & $\begin{array}{l}\text { Effect of Schinus } \\
\text { terebinthifolius on Candida } \\
\text { albicans growth kinetics, cell } \\
\text { wall formation and } \\
\text { micromorphology. }\end{array}$ & Inglês & $\begin{array}{l}\text { Alves LA; Freires } \\
\text { Ide A; Pereira } \\
\text { TM; de Souza A; } \\
\text { Lima Ede O; de } \\
\text { Castro RD } \\
\end{array}$ & $\begin{array}{l}\text { Acta Odontol Scand;71(3-4):965- } \\
71,2013\end{array}$ & 2013 \\
\hline MEDLINE & $\begin{array}{l}\text { Antimicrobial lectin from } \\
\text { Schinus terebinthifolius leaf. }\end{array}$ & Inglês & $\begin{array}{l}\text { Gomes FS; } \\
\text { Procópio TF; } \\
\text { Napoleão TH; et } \\
\text { al. }\end{array}$ & $\begin{array}{c}\text { J Appl } \\
\text { Microbiol;114(3):672-9, } 2013\end{array}$ & 2013 \\
\hline SciELO & $\begin{array}{l}\text { Atividade antifúngica de } \\
\text { produtos naturais indicados } \\
\text { por raizeiros para tratamento } \\
\text { de candidíase oral }\end{array}$ & Português & $\begin{array}{l}\text { Freire Abílio, } \\
\text { Vanessa Maria; } \\
\text { da Silva } \\
\text { Mesquita, Bruno; } \\
\text { et al. }\end{array}$ & $\begin{array}{l}\text { Revista Cubana de } \\
\text { Estomatología Set 2014, Volume } \\
51 \text { № } 3 \text { Páginas } 259 \text { - } 269\end{array}$ & 2014 \\
\hline
\end{tabular}




\begin{tabular}{|l|l|l|l|l|l|}
\hline \multirow{3}{*}{ SciELO } & $\begin{array}{l}\text { Evaluation of a preservative } \\
\text { system in a gel containing } \\
\text { hydroalcoholic extract of } \\
\text { Schinus terebinthifolius }\end{array}$ & \multirow{2}{*}{ Inglês } & $\begin{array}{l}\text { Moura, Túlio } \\
\text { Flávio A. L.; } \\
\text { Raffin, Fernanda }\end{array}$ & $\begin{array}{l}\text { Revista Brasileira de } \\
\text { Farmacognosia Jun 2011, } \\
\text { Volume 21 № 3 Páginas 532 - } \\
\text { N.; et al. }\end{array}$ & 2011 \\
\hline
\end{tabular}

Em um detalhamento mais aprofundado quanto aos estudos obtidos, boa parte vinculou-se a atividades de crescimento e inibição celular de ensaios com finalidade antifúngica, de modo a envolver diferentes espécies do Gênero Candida (TORRES et al., 2012; ALVES et al., 2012; GEHRKE et al., 2013; GOMES et al., 2013). Diante dos fatos, esse microrganismo tem despertado o interesse em diversos experimentos, por possuir baixa sensibilidade aos fármacos sintéticos, e o restrito arsenal medicamentoso no tratamento de candidíase (SILVA et al., 2020). Para tanto, o uso de produtos naturais tem sido cada vez mais constante, uma vez que cada espécie possui suas particularidades e dose concentração resposta de acordo com cada extrato (FERREIRA et al., 2020).

Por outro lado, e no aspecto evolutivo do patógeno, alguns se classificaram na temática de resistência microbiana, com objetivos mais concentrados na produção de biofilme ou biopelícula, por meio de técnicas mais aprofundadas na subárea de biologia celular e molecular em ensaios com Candida (ULUKANLI et al., 2014; BARBIERI et al., 2014; ALVES et al., 2013). Amplia-se desse modo uma variação de possibilidades em torno de um único fungo, contudo, ainda com poucos estudos nesse referido eixo. Tal justificativa se correlaciona com as condições clínicas da doença em públicos específicos, como pacientes imunossuprimidos, transplantados, acometidos por distúrbios imunológicos e portadores do vírus HIV (SILVA et al., 2018).

Pesquisas de outras modalidades também revelaram a utilização $S$. terebinthifolius na confecção de bioprodutos no combate às doenças fúngicas (TONIAL et al., 2016; FREIRE et al., 2014; MOURA et al., 2011). Com isso, há uma variedade de uso dessa espécie e seus compostos, inclusive do óleo essencial, com proposta tecnológica tanto para área medicinal em microbiologia, como também nas atividades de caráter antioxidante (COSTA et al., 2013).

Além disso, a composição dessas substâncias possui uma variedade de processos, de modo que diversas partes da planta pudessem ser exploradas, como foi o caso do extrato aquoso da casca realizado por Torres et al., (2012), das folhas por Gehrke et al., (2013), e caule (FREIRE et al., 2014), Metanol Hidroalcoólico (ULUKANLI et al., 2014); Tintura (ALVES et al., 2012; ALVES et al., 2013); Compostos isolados como E-2-hexilcinamaldeído e alcaloides de pirrolopirazina (TONIAL et al., 2016; BARBIERI et al., 2014); SteLL lectina (GOMES et al., 2013) e hidrogel (MOURA et al., 2011).

De uma forma geral, os ensaios com S. terebinthifolius apresentaram sensibilidade a diferentes espécies de Candida, porém, com variação de dose concentração resposta e o tipo de produto obtido. Ademais, esse tipo de levedura tem mostrado uma dinamicidade bem variada nos últimos anos, no que se refere ao uso de fármacos utilizados na clínica, uma vez que apresentou mecanismos de resistência devido à mutação gênica. Medicamentos sintéticos como Anfotericina B e Nistatina, além de apresentarem falhas em sua eficácia, também possuem alta toxicidade às células saudáveis do indivíduo (CAMPOS et al., 2020), o que possibilita mais um argumento na busca por compostos naturais. 


\section{CONCLUSÕES}

Ao longo desse estudo foi notório perceber a importância da produtividade cientifica quanto ao uso de produtos naturais em doenças fúngicas como a candidíase. Logo, a pesquisa indicou pouco produtividade cientifica envolvendo a espécie Schinus terebinthifolius Raddi em relação ao gênero Candida, por mais que os existentes nas bases de dados tenham demostrado um potencial promissor na inibição de crescimento desse patógeno.

Outro ponto em questão evidenciado está em torno de um subeixo denominado resistência que o fungo vem apresentando exposto nos periódicos mais atuais, à medida que a principal estrutura citada se remete ao biofilme ou biopelícula. Dessa forma, por se tratar de um experimento muito específico, o número de estudos ainda permanece reduzido. Portanto, cabe a necessidade da realização de mais pesquisas envolvendo a temática, inclusive, com o uso concomitante de seu termo popular 'Aroeira-vermelha' e 'Schinus terebinthifolius Raddi', como descritores principais nas bases de dados e facilitação de busca.

\section{REFERÊNCIAS}

ALBUQUERQUE, H. N.; CERQUEIRA, L. R. O.; ALBUQUERQUE, I. C. S.; CERQUEIRA, J. S.. O uso da fitoterapia nas Unidades Estratégia Saúde da Família em Campina Grande-PB. C\&DRevista Eletrônica da FAINOR, v.13, n.1, p.101-123, 2020.

BERMÚDEZ, G. P.; MUÑOZ, L. C.; OSPINA, M. J. N.. Biopelícula como mecanismo de resistencia en Candida albicans. Diario de campo: Resultados del desarrollo de métodos y técnicas de investigación. Universidad Colegio Mayor de Cundinamarca Bogotá, 2020.

BROOME, M. E.. Integrative literature reviews for the development of concepts. In: RODGERS, B. L.; CASTRO, A. A. Revisão sistemática e meta-análise. 2006.

CAMPOS, T.; COSENTINO, C.; UCELLI, P.; UGRINOVICH, S.L. Avaliação do comportamento de leveduras do gênero Candida a fármacos antifúngicos. Revista Ciência \& Inovação, v.5, n.1, 2020.

COSTA, E. M. M. B.; BARBOSA, A. S.; ARRUDA, T. A.; OLIVEIRA, P. T.; DAMETTO, F. R.; CARVALHO, R. A.; MELO, M D.. Estudo in vitro da ação antimicrobiana de extratos de plantas contra Enterococcus faecalis. J. Bras. Patol. Med. Lab., v.46, n.3, p.175-180, 2010.

COSTA, C. O.; D'SOUSA, R. P. R.; CASTRO, R. D.; FERNANDEZ, L. G.. Avaliação da atividade antioxidante em amostras comerciais de schinus terebinthifolius (aroeira vermelha). Rev. Ciênc. Méd. Biol, v.12, n.3, p.312-317, 2013.

DUARTE, A. M.; MASIERO, A. V.; BOFF, P.; PUCCI, M. O. Saberes e práticas populares no uso de plantas medicinais em espaço urbano no planalto sul catarinense. Revista Brasileira de Agroecologia, v.15, n.1, p.28, 2020.

FERREIRA, F. G. P.; CRUZ, G. S.; COSTA, H. P.; MEIRU, M. I. L. Evaluation of antifungal activity of the hydroalcoolic extract of Pereskia aculeata miller leaves in Candida spp. International Journal of Development Research, v.10, n.4, p.35195-35199.
NEGRI, M.; SILVA, S.; HENRIQUES, M.. Insights into Candida tropicalis nosocomial infections and virulence factors. Eur. J. Clin. Microbiol. Infect. Dis., v.31, p.1399-1412, 2012. DOI: http://doi.org/10.1007/s10096-011-1455-z

OLANDA, R. F.; BARRO, E. B.; GAVILAN, M. L.; SILVA, E. O.. Medicinal plants used in the Santo Antônio dos Pretos quilombola community (Codó Municipality, Maranhão, Brazil). Revista Ibero Americana de Ciências Ambientais, v.11, n.3, p.392-401, 2020.

PRIVATO, M. B.; MARTINEZ, L. L.; SCHMIDT, C.. Biofármacos no Brasil: uma revisão do processo de regulamentação. Arq. Med. Hosp. Fac. Cienc. Med. Santa Casa, v.65, n.1, 2020.

QUINDÓS, G.. Las micosis en el amanecer del siglo XXI. Rev. Iber. Micol, v.9, p.1-4, 2002.

ROSAS, E. C.; CORREA, L. B.; HENRIQUES, M. G.. Chapter 28 Antiinflammatory Properties of Schinus terebinthifolius and Its Use in Arthritic Conditions. Elsevier, p.489-505, 2019.

RUAS, F. G.. Seleção de genótipos, manejo e perfil químico de aroeira (Schinus terebinthifolius Raddi.) no Estado do Espírito Santo. Dissertação (Mestrado) - Universidade Federal do Espírito Santo, Vitória, 2016.

SÁ JUNIOR, P. F.; MUNIZ, E. B.; PEREIRA, N. A.; OLIVEIRA, M. A. S.. Atividade antimicrobiana in vitro dos extratos aquosos, hidroalcoólicos e alcoólicos de espécies da família anacardiaceae. Rev. Ciênc. Méd. Biol, v.15, n.1, p.56-61, 2016.

SANTOS, A. A. J. C.; BARROS, B. R. S.; AGUIAR, L. M. S.; PATRIOTA, L. L. S.. Schinus terebinthifolia leaf lectin (SteLL) is an immunomodulatory agent by altering cytokine release by mice splenocytes. Biotech, v.10, p.144, 2020. 
SIDRIM, J. J. C.; MOREIRA, J. L. B.. Fundamentos clínicos laboratoriais da micologia médica. Guanabara Koogan, 1999.

SILVA, S. L.; JÚNIOR, F. P. A.; LIMA, E. O.. Investigação de atividade antifúngica do itraconazol frente a cepas de candida. Journal of Medicine and Health Promotion, v.5, n.2, p.70-77, 2020.

SILVA, D. R.; CARVALHO, R. D. P.; RODRIGUES, A. C.; PONTES, K. T.; SILVA, A. C. B.. Os produtos naturais são uma alternativa para o tratamento da candidose oral? Uma revisão de ensaios clínicos. Arch Health Invest., v.7, n.12, p.530-534, 2018.

SILVA, A. B.; SILVA, T.; FRANCO, E. S.; RABELO, S. A.; LIMA, E. R.; MOTA, R. A.; CÂMARA, C. A. G.; PONTES FILHO, N. T.; LIMA FILHO, J. V.. Antibacterial activity, chemical composition, and cytotoxicity of leaf's essential oil from Brazilian pepper tree (Schinus terebinthifolius, Raddi). Braz. J. Microbiol, v.41 n.,1, 2010.

SOUZA, M. T.; SILVA, M. D.; CARVALHO, R.. Revisão integrativa: o que é e como fazer?. Einstein, v.8, n.1, p.102106, 2010.

SOUZA-MOREIRA, T. M.; SALGADO, H. R. N.; PIETRO, R. C. L. R.. O Brasil no contexto de controle de qualidade de plantas medicinais. Revista Brasileira de Farmacognosia, v.20, p.435-440, 2010.

WHITE, P. L.; WILLIAMS, D. W.; KURIYAMA, T. S. S. A.; LEWIS, M. A. O.; BARNES, R. A.. Detection of Candida in concentrated oral rinse cultures by realtime PCR. J. Clin. Microbiol, v.42, n.5. p.2101-2107, 2004.

A CBPC - Companhia Brasileira de Produção Científica (CNPJ: 11.221.422/0001-03) detém os direitos materiais desta publicação. Os direitos referem-se à publicação do trabalho em qualquer parte do mundo, incluindo os direitos às renovações, expansões e disseminações da contribuição, bem como outros direitos subsidiários. Todos os trabalhos publicados eletronicamente poderão posteriormente ser publicados em coletâneas impressas sob coordenação da Sustenere Publishing, da Companhia Brasileira de Produção Científica e seus parceiros autorizados. Os (as) autores (as) preservam os direitos autorais, mas não têm permissão para a publicação da contribuição em outro meio, impresso ou digital, em português ou em tradução. 